\title{
Editorial
}

\section{LEPROSY CONTROL IN 1978 AND BEYOND: WHO IS TO DO THE WORK?}

In October 1969, on these very pages, Professor Michel Lechat wrote an Editorial which might have been entitled "The World Failure of Leprosy Control". He drew attention to the fact-now increasingly clear to everyone - that the hopes raised by the introduction of the sulphones 20 years previously were not being realized. In the years since his Editorial, the position has become generally worse, and a great deal more complicated. Since the original estimate by the World Health Organization in 1965 of a world total of $10,786,000$ patients suffering from this disease, successive WHO Expert Committees have seen no reason to reduce the figure. It should, however, be stressed that it was arrived at with a number of important reservations, some of which are worth extracting here from WHO's 1966 "Guide to Leprosy Control":

(1) "The data collected or available in the literature on the prevalence of leprosy in most countries do not represent the real situation, because neither case finding nor reporting have reached the desired level".

(2) "Furthermore; in some countries the prevalence rate is apparently low because patients are discharged from case-lists as soon as the disease becomes inactive. In other countries cases of quiescent disease, especially tuberculoid, are maintained on the active list for many years. These observations as well as diff patients from control make it difficult to obtain accurate data on the prevalence of leprosy."

(3) "It is stressed that these data are presented with many reservations and are intended to give an idea of the extent of the problem throughout the world".

The fact that several large countries have consistently failed to produce estimates of the numbers of their leprosy cases, together with the continued population increase, heavily affecting those countries where leprosy is endemic, has led to a figure of 15 million being quoted in recent years by a number of experienced observers, as a more realistic one for the world total of estimated cases, and WHO's most recent re-appraisal (Expert Committee on Leprosy, Fifth Report, 1977) states that "Revised estimates from a number of the larger countries indicate the total cases throughout the world may well exceed 12 million". Of these, it is estimated that only about 3 million are known to local authorities, and that only a fraction of them receive treatment with any degree of regularity. Equally disturbing is the fact that the continued 


\section{References}

Bechelli, B. and Dominguez, V. M. (1966). Bull. Wld Hlth Org. 34, 811.

Lechat, M. F. (1969). Lepr. Rev. 40, 191.

WHO (1966). Guide to Leprosy Control. Geneva, Switzerland.

WHO (1977). Expert Committee on Leprosy, Fifth Report, Technical Report Series 607. Geneva, Switzerland. 